\title{
Correspondence
}

\section{Divers Alert Network (DAN)}

To the Editor:

Underwater diving injuries from scuba (self-contained underwater breathing apparatus) or surface supply air compressors pose a unique problem for local rescue and emergency medical system (EMS) personnel. Severe cases need to be quickly evacuated to the nearest hyperbaric or recompression chamber, which may be hundreds of miles away. Evacuation is made difficult by the fact that victims cannot be taken to a cabin altitude greater than 800 feet during air transport. In less severe cases diagnosis is difficult because there generally are no outward signs. Only the patient's subjective description of his symptoms, and his very recent history of underwater diving can be relied on to make a diagnosis. Significant otological and opthalmologic problems can result from the effects of pressure as well. Management of underwater diving injuries is not generally taught in medical school, nursing school or para-medical education programs. Scuba diving accidents are rare, roughly only 500 incidents among the 1-3 million active sport scuba divers who make an undetermined number of dives yearly. The National Diving Accident Network was established in September 1980 to assist local EMS personnel in the diagnosis, early treatment, and evacuation of underwater diving accidents. A 24-hour emergency hotline (919) 684-8111 accepts collect calls for diving accidents. A non-emergency information line (919) 684-2948 is available for medical questions related to diving, Monday-Friday 9 a.m. -5 p.m. Eastern Standard Time. Originally 100 per cent federally funded, DAN must now rely on donations from sport divers and concerned health care workers for operating funds. The DAN Underwater Diving Accident Manual describes signs, symptoms, and early treatment for each of the major diving related injuries including IV and drug administration guide- lines for EMS personnel. The manual is available for $\$ 4.00$ (U.S.) or comes as part of the package received by every member of DAN's membership association, the Divers Alert Network. For $\$ 10$ (U.S.) a year, every member receives: a membership card which lists diving accident symptoms on one side and DAN's emergency and non-emergency phone numbers on the other; a newsletter "Alert Diver" which describes diving medicine and safety information in layman's language, plus articles for the professional, case histories from DAN's accident file and medical questions related to diving from DAN's information line file. Posters and brochures are free for emergency rooms, ambulance squads, dive boats, or dive stores. Special memberships are also available for dive stores, dive clubs and corporations.

Although diving accidents are rare, the sport is growing with approximately 300,000 new divers trained each year. Diving is most heavily done around coastal areas but wherever there is an inland lake or quarry chances are it will be visited by scuba divers. Local EMS personnel need to be aware that special considerations are necessary in caring for these diving accident victims and that there is help available with the touch of a phone.

For more information write:

\section{Chris Wachholz RN}

Assistant Director

DAN (Divers Alert Network)

Box 3823

Duke University Medical Center

Durham, NC 27710 